\title{
Maternal uniparental disomy of chromosome 6
}

INSERM

\section{Source}

INSERM. (1999). Orphanet: an online rare disease and orphan drug data base. Maternal uniparental disomy of chromosome 6. ORPHA:96181

Maternal uniparental disomy of chromosome 6 is an uniparental disomy of maternal origin characterized by intrauterine growth retardation. Homozygosity for a recessive disease mutation for which only a mother is a carrier may lead to other phenotypes. 